\title{
Human chorionic gonadotropin detection in cerebrospinal fluid of patients with a germinoma and its prognostic significance: assessment by using a highly sensitive enzyme immunoassay
}

\author{
Kohei Fukuoka, MD, ${ }^{1}$ Takaaki Yanagisawa, MD, PhD, ${ }^{1}$ Tomonari Suzuki, MD, PhD, ${ }^{1}$ \\ Mitsuaki Shirahata, MD, PhD, ${ }^{2}$ Jun-ichi Adachi, MD, PhD, ${ }^{2}$ Kazuhiko Mishima, MD, PhD, ${ }^{2}$ \\ Takamitsu Fujimaki, MD, PhD, ${ }^{3}$ Hideki Katakami, MD, PhD, ${ }^{4}$ Masao Matsutani, MD, $\mathrm{PhD},{ }^{2}$ and \\ Ryo Nishikawa, MD, PhD² \\ 1'Division of Pediatric Neuro-Oncology, Department of Neuro-Oncology/Neurosurgery, and 2Department of Neuro-Oncology/ \\ Neurosurgery, Saitama Medical University International Medical Center, Hidaka; ${ }^{3}$ Department of Neurosurgery, Saitama Medical \\ University Hospital, Moroyama; and ${ }^{4}$ Division of Clinical Research Sciences, Department of Medicine, Teikyo University Chiba \\ Medical Center, Ichihara, Japan
}

OBJECTIVE Human chorionic gonadotropin (HCG) can be detected in a certain population of patients with a germinoma, but the frequency of germinoma HCG secretion and the prognostic value of HCG in the CSF are unknown.

METHODS The authors measured HCG levels in sera and CSF in patients with a histologically confirmed germinoma by using a highly sensitive assay known as an immune complex transfer enzyme immunoassay (EIA), which is more than 100 times as sensitive as the conventional method, and they analyzed the correlation between HCG levels and the prognoses of patients with a germinoma.

RESULTS HCG levels in sera and CSF of 35 patients with a germinoma were examined with the immune complex transfer EIA. The median CSF HCG levels in patients with a germinoma during the pretreatment and posttreatment evaluations were $192.5 \mathrm{pg} / \mathrm{ml}$ (range 1.2-13,116.5 pg/ml) and $18.7 \mathrm{pg} / \mathrm{ml}(1.2-283.9 \mathrm{pg} / \mathrm{ml})$, respectively. Before treatment, the CSF HCG level was greater than the cutoff value in $85.7 \%$ of the patients with a germinoma. The authors compared survival rates among the patients by using a CSF HCG cutoff level of $1000 \mathrm{pg} / \mathrm{ml}$, and the difference was statistically significant between the groups ( $p=0.029$, log-rank test).

CONCLUSIONS Results of this study demonstrate that most germinomas secrete HCG. Patients with a germinoma that secretes higher amounts of HCG in their CSF experienced recurrence more frequently than those with lower CSF HCG levels.

http://thejns.org/doi/abs/10.3171/2016.4.PEDS1658

KEY WORDS human chorionic gonadotropin; germinoma; oncology; prognosis

I NTRACRANIAL germ cell tumors (GCTs) are primary malignant CNS tumors that tend to arise along the anatomical midline, such as those in the pineal region and the neurohypophysis. ${ }^{12}$ These tumors are classified as one of two types: germinomas or nongerminomatous GCTs (NGGCTs). NGGCTs, with the exception of mature teratomas, are characterized mostly by their secretion of the tumor markers human chorionic gonadotropin (HCG) or alpha-fetoprotein (AFP); HCG has also been detected in a certain population of patients with a germinoma, but there have been few reports on the frequency of HCG secretion from germinomas. ${ }^{1,11}$ Subcategorizing germinomas based on HCG secretion remains controversial. ${ }^{1,11,13}$ In some European and American clinical trials, germinomas were classified based on serum or CSF HCG titers greater than $50 \mathrm{IU} / \mathrm{L}$, but that criterion is open to dispute..$^{2,8}$ Therefore,

ABBREVIATIONS AFP = alpha-fetoprotein; CARE = carboplatin and etoposide $;$ CR = complete response; EIA = enzyme immunoassay; $\mathrm{GCT}=$ germ cell tumor; $\mathrm{HCG}=$ human chorionic gonadotropin; ICT = immune complex transfer; NGGCT = nongerminomatous GCT.

SUBMITTED February 2, 2016. ACCEPTED April 14, 2016.

INCLUDE WHEN CITING Published online July 8, 2016; DOI: 10.3171/2016.4.PEDS1658. 
any differences in survival rates between patients with a germinoma with a high or low HCG level have not been conclusive. ${ }^{9,11,13}$ Some studies have reported no statistically significant difference in survival rates between groups based on HCG secretion level. ${ }^{11,13}$ However, these studies defined high HCG levels as serum HCG titers higher than the normal limit or $50 \mathrm{IU} / \mathrm{L} .{ }^{11-13}$

Although detection in CSF is more sensitive than that for serum according to the results of previous reports, ${ }^{1,10}$ our enzyme immunoassay (EIA) was sensitive enough to measure the lowest levels in both the sera and CSF of the examined patients. ${ }^{6,7}$ We therefore measured HCG levels in both the sera and CSF in patients with a histologically proven germinoma by using our highly sensitive EIA, which is more than 100 times more sensitive than the conventional method. ${ }^{6,7}$ We analyzed the frequency and magnitude of HCG secretion and its prognostic significance in patients with a germinoma.

Our results demonstrate that the majority of histologically proven germinomas secrete HCG, and a subset of the tumors that produce high CSF HCG levels tend to recur. These findings suggest that germinomas should be classified by using a higher HCG level than that used in past studies.

\section{Methods}

\section{Patients and Clinical Materials}

In this study, we included 46 patients whose diagnoses were established pathologically and who had CSF and blood sample records from both the pretreatment and posttreatment periods. Diagnoses included 35 germinomas, 7 NGGCTs (5 mixed GCTs with a germinoma component, 1 embryonal carcinoma, and 1 immature teratoma), and 4 other intracranial lesions (1 pilocytic astrocytoma, 1 central neurocytoma, 1 radiation-induced meningioma, and 1 radiation necrosis) that were not distinguished from GCTs preoperatively. In this cohort, we defined germinomas as tumors diagnosed pathologically without AFP elevation in both the serum and CSF at onset, regardless of HCG elevation in the serum and/or CSF, synthiotrophoblastic cell presence, and HCG positivity according to immunostaining. This investigation was approved by the ethical committee of the Saitama Medical University International Medical Center and Saitama Medical University Hospital.

\section{HCG Measurement}

We analyzed pretreatment and posttreatment HCG levels in the sera and CSF of patients with a histologically proven germinoma by using a highly sensitive assay known as an immune complex transfer (ICT) EIA. The details of ICT EIA were described elsewhere. ${ }^{6,7}$ The limits of detection using ICT EIA were $0.2 \mathrm{pg} / \mathrm{ml}$ for both sera and CSF. ICT EIA can detect equimolar quantities of intact HCG and free HCG- $\beta$. The HCG cutoff level for ICTEIA detection was set at $30 \mathrm{pg} / \mathrm{ml}$, which is the maximum level in unaffected patients. ${ }^{6}$ We excluded patients younger than 10 years and older than 50 years from this analysis because HCG cutoff levels are unknown in patients who have not attained puberty and in those who have reached menopause. 6,7
Total HCG levels were measured by using a chemiluminescence immunoassay, and free HCG- $\beta$ levels were measured via radioimmunoassay.

\section{Statistical Analysis}

For statistical analyses, subgroup comparisons were performed by using the t-test, Pearson's chi-square test, and Fisher's exact test. Overall survival was defined as the probability of survival. Progression-free survival was defined as the probability of remaining alive and free of progression or relapse. Survival curves were plotted by using the Kaplan-Meier method. The log-rank test and the Cox proportional hazards model were used to detect differences in survival rates between different groups of patients. Two-sided tests were used for all analyses, and $p$ values of $<0.05$ were considered significant. JMP 9 (SAS Institute Inc.) was used for all analyses.

\section{Results}

Clinical characteristics of the 35 patients are summarized in Table 1 and the Supplementary Tables. For diagnosis, surgical procedures included endoscopic or stereotactic biopsy (19 patients) followed by partial removal or biopsy with craniotomy (9 patients), transsphenoidal surgery ( 2 patients), and unknown methods (5 patients) (Supplementary Tables). Each patient was treated with radiotherapy and chemotherapy. Radiation fields included the whole ventricle in 25 patients; the whole brain in 7

TABLE 1. Clinical characteristics of patients with an intracranial germinoma

\begin{tabular}{lc}
\hline \multicolumn{1}{c}{ Characteristic } & Value \\
\hline Age (median [range]) (yrs) & $16.8(12.6-45.1)$ \\
\hline Male/female ratio & $31: 4$ \\
\hline Location (no.) & 11 \\
\hline Pineal & 6 \\
\hline Neurohypophysis & 5 \\
\hline Bifocal (pineal and neurohypophysis) & 3 \\
\hline Basal ganglia & 2 \\
\hline Lateral ventricle & 8 \\
\hline Multiple & \\
\hline Method of CSF collection (no.) & 49 \\
\hline Lumbar puncture & 21 \\
\hline Ventricular puncture & \\
\hline Treatment & 25 \\
\hline Radiation field (no.) & 7 \\
\hline Whole ventricle & 3 \\
\hline Whole brain & $24(23.4-30)$ \\
\hline Extended local & $3(3-8)$ \\
\hline Radiation dose (median [range]) (Gy) & 28 \\
\hline No. of CARE regimen cycles (median [range]) & 2 \\
\hline Treatment response (no.) & \\
\hline CR & \\
\hline Nearly CR & \\
\hline Unknown & \\
\hline
\end{tabular}


patients, which included all patients with basal ganglia lesions; and an extended local field, which included the whole ventricle except for the distal end of the fourth ventricle, in 3 patients. The median irradiation dose was 24 Gy (range 23.4-30 Gy). For chemotherapy, the carboplatin and etoposide (CARE) regimen, which consisted of carboplatin $\left(450 \mathrm{mg} / \mathrm{m}^{2}\right)$ on Day 1 and etoposide $\left(150 \mathrm{mg} / \mathrm{m}^{2}\right.$ per day) on Days 1-3, was administered to each patient. The median number of administered cycles of the CARE regimen was 3 (range 3-8 cycles). The treatment responses were complete response (CR) for 28 patients, nearly CR with minor enhancement for 2 patients, and unknown response for 5 patients. The median follow-up period was 63 months (range 5-154 months).

The median CSF HCG levels in patients with a germinoma during the pretreatment and posttreatment evaluations were $192.5 \mathrm{pg} / \mathrm{ml}$ (range $1.2-13,116.5 \mathrm{pg} / \mathrm{ml}$ ) and $18.7 \mathrm{pg} / \mathrm{ml}$ (range $1.2-283.9 \mathrm{pg} / \mathrm{ml}$ ), respectively, and the difference was statistically significant $(\mathrm{p}=0.003)$. Before treatment, HCG levels in the CSF were greater than the $30-\mathrm{pg} / \mathrm{ml}$ cutoff value in $85.7 \%$ of the patients with a germinoma (Fig. 1).

Using other methods for HCG examination, we detected CSF total HCG in $9(75 \%)$ of 12 patients and CSF free HCG- $\beta$ in of $13(59 \%)$ of 22 patients. CSF HCG levels detected by an ICT EIA tended to correlate with both free HCG- $\beta\left(\mathrm{R}^{2}=0.47, \mathrm{p}=0.004\right)$ and total HCG $\left(\mathrm{R}^{2}=0.11, \mathrm{p}\right.$ $=0.28$ ) levels in CSF (Supplementary Figure).

The median CSF HCG levels before treatment were $441.6 \mathrm{pg} / \mathrm{ml}$ (range 8.7-4977 pg/ml) in patients with an NGGCT and $11.0 \mathrm{pg} / \mathrm{ml}$ (range 2.9-248.9) in patients with another type of intracranial lesion. The HCG level was more than $30 \mathrm{pg} / \mathrm{ml}$ in 1 patient with an intracranial lesion whose pathological diagnosis was central neurocytoma.

After treatment, CSF HCG levels analyzed by ICT EIA were greater than the cutoff value in $9(25.7 \%)$ patients with a germinoma, and 4 of those patients had a recurrence after a median of 56 months (range 7-115 months). Those patients tended to experience recurrence more fre- quently than patients whose CSF HCG levels were under the cutoff value after treatment (4 of 9 patients vs 3 of 26 patients, respectively) although this difference was not statistically significant $(\mathrm{p}=0.055)$.

For patients with a germinoma, the estimated 4-year overall and progression-free survival rates were $100 \%$ and $85.9 \%$, respectively. Seven patients experienced recurrence during follow-up (Table 2). Pathological confirmation of recurrence was performed for 2 patients, and both diagnoses were germinoma recurrence. Almost every patient treated for recurrent tumors achieved CR, except for 1 patient whose tumor recurred with an elevation in both HCG and AFP levels. The recurrent tumor appeared to have undergone malignant transformation from a germinoma to a highly malignant GCT, such as a yolk sac tumor, or to have expanded from a component overlooked during the first surgery. The CSF HCG levels at onset were greater than $1000 \mathrm{pg} / \mathrm{ml}$ in 5 of 7 patients with recurrence (Fig. 1). Three of the 5 patients experienced recurrence more than 5 years after onset. We compared survival rates between the patients with CSF HCG levels greater than $1000 \mathrm{pg} / \mathrm{ml}$ and those with level less than $1000 \mathrm{pg} / \mathrm{ml}$, and the difference between the groups was statistically significant ( $p=0.029$ ) (Fig. 2), although serum HCG levels did not affect the prognoses of patients with a germinoma.

\section{Discussion}

In this study we examined HCG secretion in intracranial germinomas and its impact on patient prognoses. A subset of germinomas reportedly secrete HCG. ${ }^{1,5,10,11} \mathrm{Al}-$ len et al. ${ }^{1}$ reported serum and CSF HCG values in 58 newly diagnosed patients with a histologically confirmed germinoma. CSF HCG was detected in $22(37.9 \%)$ patients with a germinoma, whereas HCG was detected in only the sera of $3(5.2 \%)$ patients. In another study by Ogino et al., ${ }^{11} 11(69 \%)$ of 16 patients had high HCG levels in their $\mathrm{CSF}$, but the patient group included patients whose tumors were diagnosed without histological confirmation. In our

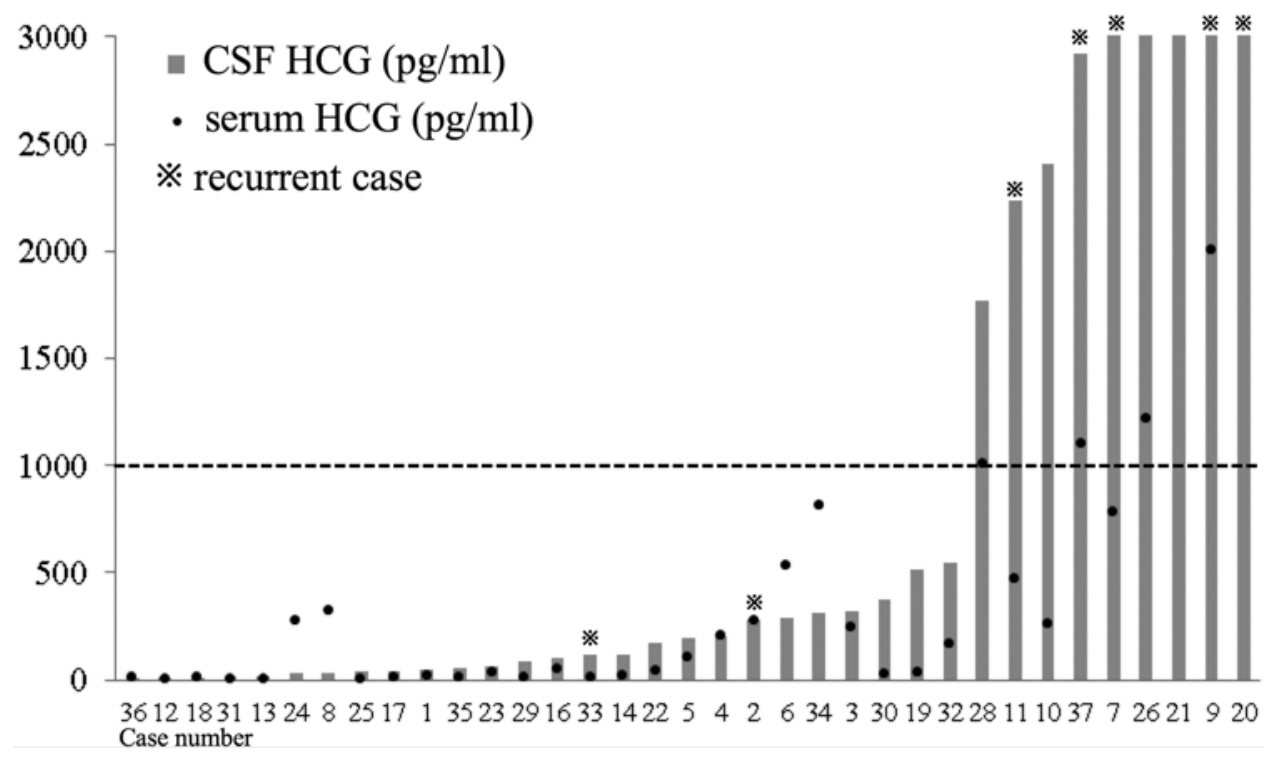

FIG. 1. Human chorionic gonadotropin levels in CSF and serum in each patient. 
TABLE 2. Clinical characteristics of patients with a recurrent germinoma

\begin{tabular}{|c|c|c|c|c|c|c|c|c|c|c|}
\hline \multirow{3}{*}{$\begin{array}{l}\text { Case } \\
\text { No. }\end{array}$} & \multirow{3}{*}{$\begin{array}{l}\text { Age } \\
\text { (yrs), } \\
\text { Sex }\end{array}$} & \multirow[b]{3}{*}{ Location } & \multicolumn{4}{|c|}{ HCG Levels (pg/ml) Measured by ICT EIA } & \multirow{3}{*}{$\begin{array}{l}\text { Time to } \\
\text { Recurrence } \\
\text { (mos) }\end{array}$} & \multirow{3}{*}{$\begin{array}{l}\text { Location at Recurrence } \\
\text { (relationship w/ initial } \\
\text { radiation field) }\end{array}$} & \multirow{3}{*}{$\begin{array}{l}\text { Pathological } \\
\text { Confirmation at } \\
\text { Recurrence }\end{array}$} & \multirow{3}{*}{$\begin{array}{l}\text { Tx Response } \\
\text { of Recurrent } \\
\text { Tumor }\end{array}$} \\
\hline & & & \multicolumn{2}{|c|}{ Before Tx } & \multicolumn{2}{|c|}{ After Tx } & & & & \\
\hline & & & Serum & CSF & Serum & CSF & & & & \\
\hline 2 & $25, M$ & $\mathrm{P}, \mathrm{NHP}$ & 279.9 & 279.9 & 4.9 & 17.9 & 41 & $\begin{array}{l}\text { Frontal subdural space } \\
\text { (outside) }\end{array}$ & Yes (germinoma) & $\mathrm{CR}$ \\
\hline 9 & $40, M$ & Lat ventricle & $2,007.0$ & $10,975.0$ & 10.9 & 92.2 & 18 & Spine (outside) & No & $\mathrm{CR}$ \\
\hline 10 & $24, \mathrm{M}$ & NHP & 259.1 & $2,408.6$ & 22.2 & 15.6 & 67 & Spine (outside) & No & $\mathrm{CR}$ \\
\hline 11 & $14, \mathrm{M}$ & NHP, medulla & 470.2 & $2,235.1$ & 188.9 & 283.9 & 115 & Spine (outside) & No & CR \\
\hline 20 & $16, M$ & $\mathrm{P}$ & $5,851.1$ & $13,116.3$ & 6.8 & 15.5 & 30 & Lat ventricle (inside) & Yes (germinoma) & $\mathrm{CR}$ \\
\hline 33 & $18, M$ & $\mathrm{P}$, frontal & 15.5 & 114.1 & 7.0 & 82.2 & 7 & Spine (outside) & No (AFP elevated) & PD \\
\hline 37 & $15, F$ & P, NHP & $1,103.7$ & $2,925.2$ & 37.5 & 131 & 94 & Spine (outside) & No & $\mathrm{CR}$ \\
\hline
\end{tabular}

$\mathrm{NHP}=$ neurohypophysis; $\mathrm{P}=$ pineal; $\mathrm{PD}=$ progressive disease $; \mathrm{Tx}=$ treatment.

study, CSF HCG levels exceeded the cutoff level in $85.7 \%$ of the patients with a pathologically confirmed germinoma during pretreatment evaluation. Our data suggest that almost all germinomas secrete HCG, and the term "HCGproducing germinoma" might be redundant.

Regarding the correlation between HCG levels and the prognosis of patients with a germinoma, our analysis shows that germinomas should be subcategorized using higher HCG levels than those used in past studies. Regarding serum HCG levels, we cannot determine a serum cutoff value for the risk stratification of germinoma.

The data in this retrospective study were assessable because all tumor diagnoses were confirmed pathologically, and most patients received similar treatments. However, this research has some limitations. First, the tumors may have been misclassified because of the limited sample obtained. In particular, some patients with a germinoma and elevated HCG levels may have had a choriocarcinoma component outside the specimen used for pathological diagnosis. However, it is impossible to determine the precise component of GCTs unless we remove them en bloc, which cannot and should not be done. Hence, good responsiveness of both the initial and recurrent tumors may

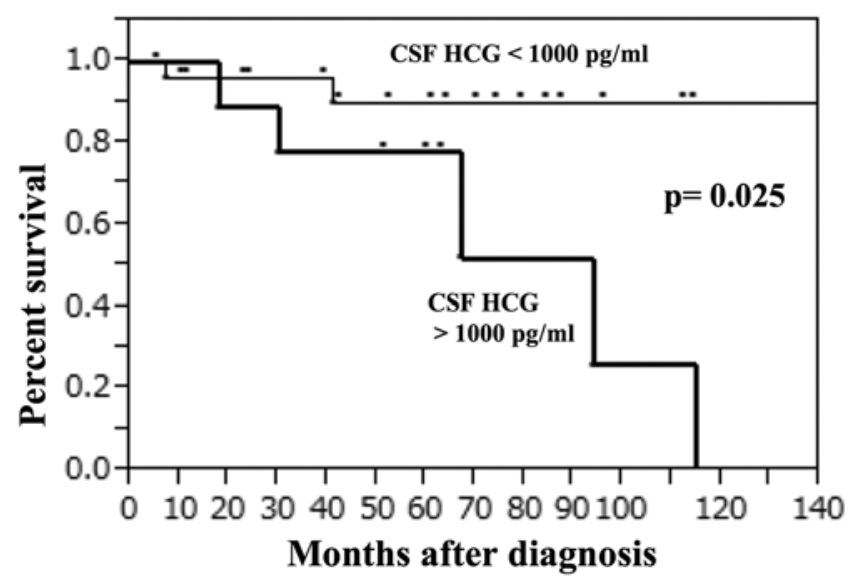

FIG. 2. Estimated survival rates of patients with germinoma and a CSF HCG level higher than $1000 \mathrm{pg} / \mathrm{ml}$ compared to patients with a CSF HCG level lower than $1000 \mathrm{pg} / \mathrm{ml}$. Kaplan-Meier curves show the probability of progression-free survival. imply diagnostic accuracy in almost all cases. Second, our number of patients was small; thus, we need to validate the relationship between CSF HCG levels and prognoses of patients with a germinoma in a larger cohort. Third, in this cohort, we have few data about total HCG values using the most sensitive commercially available HCG testing kits, which are more popular than the ICT-EIA method and the assays recommended for measuring HCG by clinical practice guidelines for extracranial GCTs given by the American Society of Clinical Oncology. ${ }^{3}$ Last, we need to remember that tumors other than GCTs can secrete HCG. ${ }^{4}$ Among intracranial lesions, craniopharyngioma and Langerhans cell histiocytosis can produce HCG also. Therefore, the presence of HCG is not always the hallmark for a GCT diagnosis.

\section{Conclusions}

We analyzed HCG levels in the sera and CSF of patients with a histologically proven germinoma using the highly sensitive ICT-EIA method. Results of this study suggest that the majority of germinomas can secrete HCG. Patients with germinomas that secreted extremely high amounts of HCG, more than $1000 \mathrm{pg} / \mathrm{ml}$ in CSF, experienced recurrence more frequently.

\section{References}

1. Allen J, Chacko J, Donahue B, Dhall G, Kretschmar C, Jakacki R, et al: Diagnostic sensitivity of serum and lumbar CSF bHCG in newly diagnosed CNS germinoma. Pediatr Blood Cancer 59:1180-1182, 2012

2. Calaminus G, Kortmann R, Worch J, Nicholson JC, Alapetite C, Garrè ML, et al: SIOP CNS GCT 96: final report of outcome of a prospective, multinational nonrandomized trial for children and adults with intracranial germinoma, comparing craniospinal irradiation alone with chemotherapy followed by focal primary site irradiation for patients with localized disease. Neuro Oncol 15:788-796, 2013

3. Gilligan TD, Seidenfeld J, Basch EM, Einhorn LH, Fancher T, Smith DC, et al: American Society of Clinical Oncology Clinical Practice Guideline on uses of serum tumor markers in adult males with germ cell tumors. J Clin Oncol 28:3388-3404, 2010

4. Iles RK, Delves PJ, Butler SA: Does hCG or hCG $\beta$ play a role in cancer cell biology? Mol Cell Endocrinol 329:62-70, 2010 
5. Inamura T, Nishio S, Ikezaki K, Fukui M: Human chorionic gonadotrophin in CSF, not serum, predicts outcome in germinoma. J Neurol Neurosurg Psychiatry 66:654-657, 1999

6. Katakami H, Hashida S, Wakisaka S, Matsutani M: Usefulness of highly sensitive immunoassay to detect CSF and serum HCG in the diagnosis and clinical course of CNS germinoma (volume 2: Quantification of HCG gene and protein expression in the tumor specimen). Folia Endocrinol Jpn 80 Suppl:84-86, 2004

7. Katakami H, Hashida S, Yamaguchi H, Yazawa S, Nakano S, Wakisaka S: Diagnosis and course of treatment of CNS germinoma: Development and clinical application of highly sensitive immune complex transfer enzyme immunoassay to detect HCG- $\beta$. Folia Endocrinol Jpn 79 Suppl:58-60, 2003

8. Kellie SJ, Boyce H, Dunkel IJ, Diez B, Rosenblum M, Brualdi L, et al: Primary chemotherapy for intracranial nongerminomatous germ cell tumors: results of the second international CNS germ cell study group protocol. J Clin Oncol 22:846-853, 2004

9. Kim A, Ji L, Balmaceda C, Diez B, Kellie SJ, Dunkel IJ, et al: The prognostic value of tumor markers in newly diagnosed patients with primary central nervous system germ cell tumors. Pediatr Blood Cancer 51:768-773, 2008

10. Legault G, Allen JC: Potential role of ventricular tumor markers in CNS germ cell tumors. Pediatr Blood Cancer 60:1647-1650, 2013

11. Ogino H, Shibamoto Y, Takanaka T, Suzuki K, Ishihara S, Yamada T, et al: CNS germinoma with elevated serum human chorionic gonadotropin level: clinical characteristics and treatment outcome. Int J Radiat Oncol Biol Phys 62:803-808, 2005

12. Rosenblum MK, Nakazato Y, Matsutani M: CNS germ cell tumors, in Louis DN, Ohgaki H, Wiestler OD, et al (eds): WHO Classification of Tumors of the Central Nervous System. Lyon: IARC Press, 2007, pp 198-204

13. Shin KH, Kim IH, Choe G: Impacts of elevated level of hCG in serum on clinical course and radiotherapy results in the histology-confirmed intracranial germinomas. Acta Oncol 40:98-101, 2001

\section{Disclosures}

The authors report no conflict of interest concerning the materials or methods used in this study or the findings specified in this paper.

\section{Author Contributions}

Conception and design: Fukuoka, Yanagisawa, Matsutani, Nishikawa. Acquisition of data: Fukuoka, Suzuki, Katakami. Analysis and interpretation of data: Fukuoka, Katakami. Drafting the article: Fukuoka. Critically revising the article: Katakami, Matsutani, Nishikawa. Reviewed submitted version of manuscript: Suzuki, Adachi, Mishima, Fujimaki, Matsutani, Nishikawa. Approved the final version of the manuscript on behalf of all authors: Fukuoka. Statistical analysis: Fukuoka. Administrative/ technical/material support: Suzuki, Shirahata, Adachi, Katakami, Matsutani, Nishikawa. Study supervision: Yanagisawa, Shirahata, Mishima, Fujimaki, Katakami, Matsutani, Nishikawa.

\section{Supplemental Information Online-Only Content}

Supplemental material is available with the online version of the article.

Supplementary Tables and Figure. http://thejns.org/doi/ suppl/10.3171/2016.4.PEDS1658.

\section{Correspondence}

Kohei Fukuoka, Division of Pediatric Neuro-Oncology, Department of Neuro-Oncology/Neurosurgery, Saitama Medical University International Medical Center, Yamane 1397-1, Hidakashi, Saitama-ken 350-1298, Japan. email: kohfukuoka@gmail. com. 